Revista de Economia Política, vol. 41, nº 2, pp. 236-253, abril-junho/2021

\title{
Panem et circenses: a propósito da macroeconomia da pandemia*
}

\author{
Panem et circenses: on the macroeconomics of the pandemic
}

FRANCISCO EDUARDO PIRES DE SOUZA**

RESUMO: O presente texto destaca duas características que singularizam a macroeconomia da pandemia: a interdição de parte do consumo e da produção, pelas políticas de saúde pública; e um importante processo de redistribuição de renda que resulta das políticas destinadas a mitigar os efeitos da paralisia econômica sobre a saúde financeira de indivíduos e empresas. Um aspecto central deste segundo processo é a transferência de renda do setor público para o privado, que resulta em aumento da despoupança do setor público e elevação da poupança privada. A consequência é uma forte alteração da riqueza líquida dos diferentes setores da sociedade. As estimativas feitas neste trabalho indicam que entre fevereiro e agosto de 2020, no Brasil, o setor privado obteve um ganho de riqueza líquida de quase $12 \%$ do PIB.

PALAVRAS-CHAVE: Macroeconomia da pandemia; efeitos macroeconômicos da COVID-19 no Brasil; dívida pública e poupança privada na pandemia.

ABSTRACT: This paper is about the consequences of pandemics on the macroeconomic behavior, with an empirical analysis of such effects on the Brazilian economy. Two features of the macroeconomic of pandemics are highlighted: the emergence of a dual economy, in which we have the coexistence of a sector where consumption and production are impaired by public health policies, side by side with a full employment sector; and a large redistribution of income between the public and the private sectors. Regarding the latter, we found that the redistribution had strong effects on the flows of savings in the Brazilian economy, and consequently on the stocks of net wealth: there was a sharp rise in public debt and an increase in private net wealth of $12 \%$ of GDP.

KEYWORDS: Pandemics macroeconomics; macroeconomic effects of COVID-19 in Brazil; public debt and private savings in pandemics.

JEL Classification: E01; E21; E25; H51.

\footnotetext{
* Agradeço a L.C. Bresser Pereira por um intercâmbio de ideias produtivo, que me ajudou a formular com mais clareza um ponto essencial deste artigo, a respeito das razões do aumento da poupança privada. Agradeço também a Antônio Luis Licha, Margarida Gutierrez, Marcelo Introini, Vitória Hoff e André Coletti, membros do meu grupo de pesquisa, pela discussão das ideias e dos temas tratados no presente trabalho.

** Professor do Instituto de Economia da Universidade Federal do Rio de Janeiro - UFRJ, Rio de Janeiro/ RJ, Brasil. E-mail: fepsouza@ie.ufrj.br. Orcid: https://orcid.org/0000-0001-6795-8633. Submetido: 1/ Junho//2020; Aprovado: 10/Junho/2020.
} 


\section{INTRODUÇÃO}

Existe uma macroeconomia da pandemia? A pergunta poderia ser também a respeito da existência ou não de uma macroeconomia da guerra. E a resposta, a meu ver é que sim: existe uma (macro)economia da guerra e uma (macro)economia da pandemia. E a razão é que, em ambos os casos, tanto a natureza do "problema macroeconômico" como a natureza da solução para este problema, isto é a política macroeconômica apropriada, são singulares e diferentes da macroeconomia usual seja esta referida a uma economia em situação de desemprego ou de pleno emprego.

Sobre a economia da guerra, Keynes (1940) vira de ponta-cabeça tanto o seu diagnóstico quanto seu receituário de política macroeconômica de quatro anos antes, ao fazer sua proposta sobre como pagar pela guerra. Tratava-se então de uma economia da escassez e não mais a da abundância, que havia inspirado a “Teoria Geral”. A escassez de poupança tornava imperiosa a necessidade de conter o consumo, e o objetivo de Keynes era apresentar um plano para alcançar este objetivo de forma compatível com os interesses das camadas de renda mais baixa da população. Nada mais distante das questões de sua obra clássica.

Quanto à economia da pandemia, ao contrário de sua congênere da guerra, é uma macroeconomia da recessão. Mas não de uma recessão como todas as outras que têm sido estudadas pelos economistas desde a grande depressão dos anos 1930. Agora estamos diante de uma recessão muito diferente, que exige, também, remédios bastante distintos dos conhecidos. A começar pelo fato de que a recessão, neste caso, é um evento necessário, e até mesmo desejável, se o objetivo nacional maior for o de salvar vidas. Por isso mesmo, seria um contrassenso se a política econômica tivesse como objetivo (pelo menos numa primeira fase) estimular a economia ou tentar promover a recuperação econômica.

Diante de epidemias como a gripe espanhola (1918-1920) e a COVID-19, caracterizadas pelo alto nível de contágio e ausência de vacinas ou tratamentos eficientes no momento de sua ocorrência, o principal instrumento para salvar vidas é o isolamento social. E este requer evitar as aglomerações que ocorrem nas atividades de transporte, no consumo de bens e serviços "intensivos em contato" e no trabalho presencial. Ou seja, o isolamento social exige a redução do consumo e da produção e, portanto, a recessão. Em outras palavras, a recessão é a principal medida de saúde pública (Baldwin e di Mauro 2020), pelo menos enquanto a epidemia não chega a um ponto avançado de sua fase descendente. No curto prazo, uma política exitosa de contenção da epidemia, para achatar a curva, leva a uma parada brusca da produção (Gourinchas 2020).

É verdade que há disparidades de eficiência no enfrentamento deste dilema entre saúde e economia, como resultado da qualidade das políticas de intervenção não farmacológicas, de sua tempestividade e dos hábitos e cultura da população ${ }^{1}$.

\footnotetext{
${ }^{1}$ Um dos exemplos mais notórios de sucesso no enfrentamento do dilema é o da Coreia do Sul. Este país logrou manter o número de infecções e fatalidades em nível irrisório, ao mesmo tempo em que teve
} 
Além do mais, como mostraram Correia, Luck e Verner (2020) em seu estudo sobre os efeitos da gripe espanhola em diferentes estados norte-americanos, políticas mais rigorosas de lockdown tendem a dar melhores resultados econômicos no longo prazo do que políticas menos severas.

Feitas as ressalvas acima, não há dúvida de que há, coeteris paribus, um trade-off entre recessão e epidemia: quanto mais atividades interditadas (e, portanto, mais profunda a recessão), maiores os efeitos positivos em termos de contenção da epidemia. Portanto, se o objetivo na área da saúde é o principal, o objetivo da política econômica, na fase ascendente da epidemia, não é estimular a economia e sim conter os danos às famílias vulneráveis e às empresas. Manter famílias vulneráveis e empresas "no respirador" não apenas preserva vidas e o sistema produtivo até o momento da recuperação, como contribui para manter os fluxos de pagamentos e evitar uma crise financeira que, sem dúvida, agravaria bastante a crise.

Dada a abrangência e duração das políticas de interdição do funcionamento de vastos setores da economia, a política de socorro a pessoas vulneráveis e a empresas ganhou proporções gigantescas, impondo um custo fiscal sem precedentes para a maioria dos países. De acordo com o FMI (Fiscal Monitor 2020), as medidas fiscais anunciadas até o início de setembro de 2020 equivaliam a $12 \%$ do PIB mundial devendo levar a dívida pública global ao nível de 100\% do PIB, o mais alto já registrado na história.

Há, em suma, uma combinação inédita de choques - sanitário, comportamental e de políticas econômicas - que nos permitem falar de uma macroeconomia da pandemia. Creio que suas características essenciais derivam de dois processos que são deflagrados pela pandemia:

a) o primeiro deles é a interrupção forçada e prolongada de partes importantes do fluxo circular da economia; seja por imposição legal, seja por imposição do medo, ocorre a interdição de parte da oferta e da demanda de bens, e sobretudo de serviços, da economia;

b) o segundo é um importante processo de redistribuição de renda que decorre da resposta dos governos à pandemia: tanto uma redistribuição pessoal da renda como uma redistribuição setorial e inter-regional.

É a combinação destes dois processos (a economia interditada e o processo de redistribuição) que vai determinar mudanças drásticas na composição dos fluxos macroeconômicos de produção, gastos e renda, com importantes implicações sobre os mecanismos de financiamento macroeconômico. Os desafios para a política econômica são enormes, mas argumentaremos aqui que, se a epidemia cria os problemas, ela também oferece (ao menos em parte) a solução.

$\mathrm{Na}$ seção a seguir, vamos começar pelo primeiro processo acima, que é a natureza específica da recessão causada pela pandemia. Na segunda seção discutiremos a redistribuição de renda causada pelas políticas de enfrentamento à pandemia, colocando o foco sobre a distribuição entre setores institucionais, e suas consequên-

uma queda do PIB de apenas 3,2\% no $2^{\circ}$ trimestre de 2020 - o segundo melhor desempenho (perdendo apenas para a China) dos 23 países cujo PIB foi divulgado pela OECD para aquele período. 
cias macroeconômicas. Nossa análise quantitativa se baseará no caso brasileiro, mas forneceremos evidências empíricas que mostram que o ocorrido no Brasil é muito semelhante ao que se verificou no resto do mundo, ou seja, podemos generalizar nossas conclusões. Na terceira seção examinaremos as consequências das mudanças nos fluxos macroeconômicos sobre o estoque de riqueza líquida dos diferentes setores institucionais, o que nos permitirá mostrar como a epidemia também trouxe soluções para os problemas por ela criados. A última seção do texto explora possíveis implicações da análise desenvolvida nas seções anteriores.

\section{PANEM ET CIRCENSES}

A expressão "pão e circo" neste texto não tem relação com o populismo e sim com a característica dual da economia no período da pandemia: de um lado, um segmento cuja atividade mais representativa é a da indústria alimentícia (que denominaremos, por simplicidade, de setor pão); de outro, uma parcela da economia intensiva em contato, e, portanto, em aglomeração (que denominaremos de setor circo).

A caracterização a seguir da economia dual se aplica a um amplo conjunto de países onde os governos adotaram um pacote de políticas econômicas inédito por sua ousadia. A famosa expressão de Draghi - "do whatever it takes" - traduz muito bem as características e dimensões de tais pacotes de políticas. Fazer o necessário para deter o espraiamento da epidemia e o colapso dos sistemas de saúde significou paralisar parte importante das atividades do setor circo por períodos de tempo bastante elevados (e em alguns casos com recorrência), enquanto fazer todo o necessário para conter danos às famílias e empresas levou a transferências dos governos para o setor privado incrivelmente elevadas. Os choques exógenos e as respostas da economia a eles podem ser descritos através dos seguintes fatos estilizados:

a) A renda do trabalho cai, mas as transferências do governo compensam (em muitos casos mais do que compensam) a queda da renda do trabalho. Com isso, a renda disponível do setor privado aumenta em termos relativos e, quase sempre, também em termos absolutos.

b) As camadas da população de renda mais baixa, que tem baixíssima propensão a poupar e que tiveram que reduzir seu consumo de produtos provenientes do setor circo, usam sua renda expandida para aumentar seu consumo de produtos do setor pão.

c) As camadas da população de renda mais alta, que tiveram sua renda parcialmente preservada e foram obrigadas a restringir drasticamente o consumo de produtos do setor circo, em vez de aumentar o consumo de bens do setor pão (dada a inelasticidade de sua renda por tais produtos), aumentam a sua poupança;

d) Como resultado de (b) e (c), cria-se um excesso de demanda no setor pão, enquanto o setor circo mantém sua produção muito abaixo da capacidade.

e) Sendo o setor circo mais intensivo em trabalho do que o setor pão, o des- 
emprego cresce muito na economia. Ao mesmo tempo, o setor pão fica sobreaquecido, eleva seus preços e corrói parcialmente os rendimentos reais da população de mais baixa renda.

Essa dualidade da economia cria um dilema para a política econômica: prosseguir com as políticas de apoio a empresas e famílias do setor circo gera inflação crescente no setor pão; mas retirar o apoio pode fazer a economia mergulhar numa depressão. A solução para o dilema depende da desinterdição completa do setor circo. Mas esta não é viável enquanto não houver uma vacina ou, na ausência dela, enquanto a população suscetível à doença não tiver sido reduzida a níveis compatíveis com a imunidade de rebanho numa economia liberada².

\section{A economia dual: o caso brasileiro}

A economia brasileira foi afetada substancialmente pelas medidas de lockdown adotadas pelos governos estaduais a partir de meados do mês de março de 2020 . Num primeiro momento quase todos os setores sofreram quedas fortes do nível de atividades, as exceções ficando por conta, principalmente, dos setores agropecuário e do comércio de bens essenciais - sobretudo alimentos e remédios. Mas antes mesmo do início do relaxamento das medidas de distanciamento social, vários segmentos da economia voltaram a funcionar, estabelecendo-se pouco a pouco uma linha demarcatória entre setores que continuaram interditados e outros que passaram a responder a um forte impulso pelo lado da demanda e tiveram uma retomada em "V".

A indústria de transformação é um claro exemplo dessas atividades que foram liberadas e tiveram uma recuperação em "V". Após uma queda substancial no mês de abril, a indústria manufatureira passou a crescer rapidamente e, já no mês de setembro, havia superado os níveis de produção pré-pandemia. A maior parte da indústria pertence ao segmento da economia que chamamos acima de setor pão.

Enquanto algumas poucas atividades industriais ainda permaneciam em níveis deprimidos, 14 das 25 atividades (representando 61\% do valor agregado) já haviam alcançado, seis meses após o início da pandemia no país, um nível de produção superior ao pré-pandemia, sendo que 9 delas haviam superado em mais de $5 \%$ o nível pré-pandemia. Entre estas últimas pode-se destacar: produtos alimentícios $(+$ $6,6 \%)$, minerais não metálicos $(+9,8 \%)$, onde se concentram os materiais de construção, e equipamentos de informática $(+18,3 \%)$, como se vê no Gráfico 1 a seguir. Neste contexto de aquecimento econômico, sondagem da CNI (2020), divulgada em outubro, apontou que em $41 \%$ das empresas consultadas a demanda encontrava-se acima da capacidade de produção.

\footnotetext{
${ }^{2}$ Para a epidemia não voltar a entrar numa fase ascendente é necessário que o número efetivo de reprodução, $\mathrm{R}_{\mathrm{e}}$, seja menor ou igual a 1 . Mas este não é independente dos comportamentos, inclusive da retomada das atividades produtivas. Conforme Aronson, Brassey e Kamal (2020) " $R_{e}$ is affected by the number of people with the infection and the number of susceptibles with whom infected people are in contact. People's behaviour (e.g., social distancing) can also affect $\mathrm{R}_{\mathrm{e}}$ ". Ou seja, o Limite da Imunidade de Rebanho sobe quando a economia é liberada.
} 
Gráfico 1: Índices de Produção da Indústria de

Transformação em Set/2020 (Fev/20 =100)

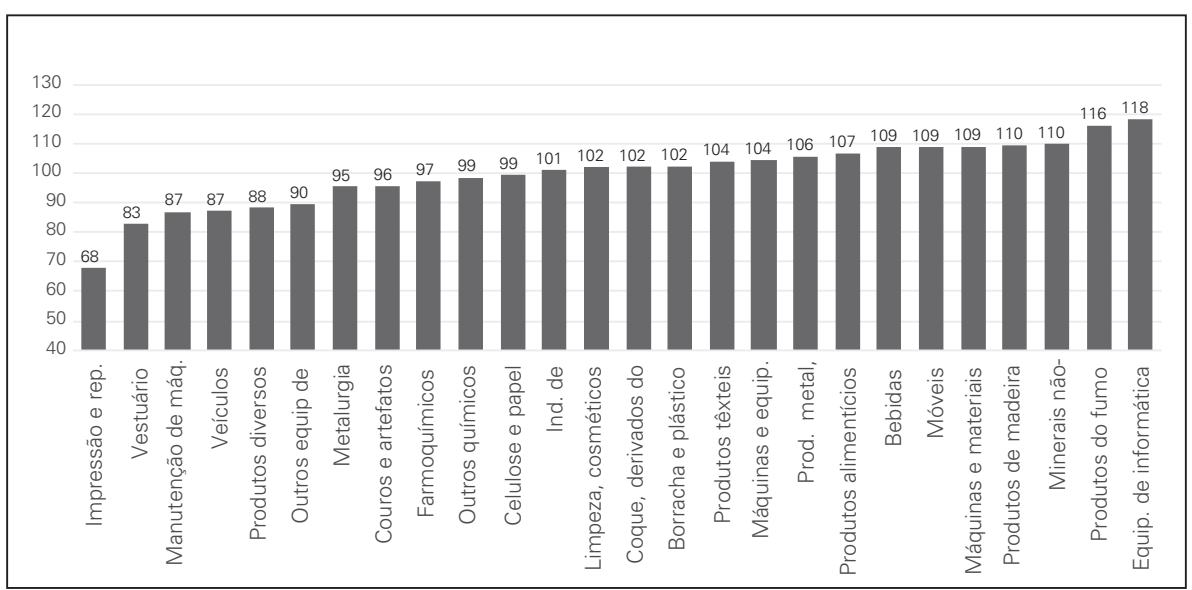

Fonte: IBGE.

O aquecimento da demanda também se refletiu na inflação que, medida pelo IPCA, apresentou deflação até o mês de maio e depois passou a sofrer uma aceleração, acumulando alta de $2,4 \%$ entre junho e outubro $(5,6 \%$ em termos anualizados). O IPCA desagregado por itens e subitens mostra elevações fortes de preços em segmentos que estão se defrontando com excesso de demanda, e não apenas nos comercializáveis (caso em que o excesso de demanda viabiliza o repasse do aumento da taxa de câmbio), mas também em não comercializáveis. A Tabela $1 \mathrm{a}$ seguir destaca os itens e (alguns) subitens em que a alta de preços ao consumidor nos 10 primeiros meses de 2020 tem sido mais importante.

Tabela 1: Inflação medida pelo IPCA: itens selecionados(1)

\begin{tabular}{lc} 
Mês & \% acumulado janeiro-outubro/2020 \\
Índice geral & $2,2 \%$ \\
Alimentação no domicílio & $12,0 \%$ \\
Revestimento de piso e parede & $8,5 \%$ \\
Cimento & $16,2 \%$ \\
Tijolo & $28,8 \%$ \\
Telha & $9,4 \%$ \\
Aparelhos eletroeletrônicos & $9,7 \%$ \\
Conserto de bicicleta & $9,8 \%$ \\
Joias e bijuterias & $13,7 \%$ \\
Pneu & $10,1 \%$ \\
Bicicleta & $9,7 \%$ \\
Acesso à internet & $8,5 \%$ \\
\hline
\end{tabular}

Fonte: IBGE.

(1) Foram selecionados itens com peso superior a 0,2\% e com taxa de variação superior a $7 \%$ no acumulado do ano e também no pós-pandemia. Para evitar um excesso de informações, foram excluídos da tabela os subitens de algumas categorias que abrigavam muitos produtos preenchendo os critérios acima, como subitens de alimentos e de aparelhos eletroeletrônicos 
Em contraste com o comportamento da indústria, o setor de serviços a partir do choque inicial, nos meses de março e abril, teve uma recuperação vagarosa e parcial, na medida em que muitas de suas atividades permaneceram interditadas ou autorizadas a funcionar apenas com capacidade reduzida. Não se trata neste caso de uma clássica restrição de oferta - caso em que se observaria pressão inflacionária também neste setor. Não só os estabelecimentos foram impedidos de funcionar como a demanda por eles também desapareceu. E mesmo quando há a reabertura parcial, a demanda continua relativamente fraca - e não por razões tradicionais, mas pelo receio de parte da população de voltar a consumir serviços intensivos em contato. A consequência é uma combinação de produção baixa e inflação também baixa (quando não deflação), nestes setores, que fazem parte do que denominamos antes como setor circo.

No mês de agosto, 5 meses após o início da pandemia, a produção de serviços ainda se encontrava $10 \%$ abaixo do último dado pré-pandemia (fevereiro de 2020). $\mathrm{E}$ alguns setores, entre os mais atingidos pela pandemia, como "serviços prestados às famílias", "serviços de alojamento e alimentação" e "transporte aéreo", ainda se encontravam em nível mais de $40 \%$ abaixo do nível de fevereiro.

O comportamento tão diferenciado entre o setor pão e o setor circo, tem a ver não apenas com as políticas de isolamento social, mas também com as medidas de política econômica destinadas à contenção de danos a empresas e famílias. A subseção a seguir colocará o foco sobre elas.

\section{As medidas de enfrentamento da pandemia e seus impactos sobre a distribuição de renda no Brasil}

Por sua dimensão inédita, os pacotes de enfrentamento da pandemia, adotados em quase todos os países, tiveram impacto substancial nos fluxos macroeconômicos. Alteraram a distribuição da renda e os fluxos de consumo e poupança.

Tipicamente, as medidas adotadas concentraram-se em ações no plano fiscal e no campo da provisão de liquidez e crédito. Neste trabalho nos concentraremos na parte fiscal das medidas de socorro, já que foram estas que tiveram efeitos mais nítidos sobre o tema que estamos tratando, que é a redistribuição de renda e as mudanças nos fluxos macroeconômicos.

Vamos decompor aqui as medidas fiscais em dois grandes grupos: o aumento de gastos públicos - principalmente na forma de gastos na área da saúde - e o aumento nas "transferências líquidas de impostos". Ambas as categorias têm efeitos importantes sobre a economia, mas a última impacta diretamente a distribuição da renda, ao reduzir a renda disponível do setor público e aumentar a renda disponível do setor privado.

Para ilustrar o volume e as consequências das medidas, apresentaremos a seguir alguns dados contundentes da resposta à pandemia no caso brasileiro. Na segunda seção apresentaremos também alguns dados internacionais que mostram a universalidade do fenômeno.

No Brasil, o componente "transferência menos impostos" do pacote fiscal foi 
o predominante. A partir dos dados disponibilizados pelo Ministério da Economia sobre a execução orçamentária até agosto e da previsão para os valores remanescentes até o final de 2020, montamos uma agregação em 4 categorias das receitas e despesas extraordinárias associadas ao enfrentamento da pandemia. A Tabela 2 a seguir apresenta esses valores em percentagem do PIB.

Se ao impacto direto de $8,6 \%$ do PIB (última linha da tabela) somarmos os impactos indiretos, o déficit fiscal prévio e os juros da dívida pública, chegamos a um déficit público em 2020, medido pelas necessidades de financiamento do governo geral (mais Banco Central), de 17,4\% do PIB, valor sem precedentes desde o Plano Real e 11,4 pontos percentuais do PIB acima do resultado de 2019. A questão do financiamento deste extraordinário aumento do déficit será discutida na segunda seção deste texto. Por ora vamos focar nas implicações distributivas do pacote.

Tabela 2: Impactos fiscais e distributivos das medidas econômicas adotadas para enfrentar a COVID-19

\begin{tabular}{|c|c|c|}
\hline Medidas com impacto no resultado primário: & (R\$ bilhōes) & $\% \mathrm{PIB}(* *)$ \\
\hline Abdicação de receitas fiscais & 20,6 & $0,3 \%$ \\
\hline Transferências e subsídios ao setor privado & 454,0 & $6,4 \%$ \\
\hline das quais, transferências a pessoas & 396,9 & $5,6 \%$ \\
\hline Gastos de Consumo $\left({ }^{*}\right)$ & 35,4 & $0,5 \%$ \\
\hline Transf. Estados e municípios por conta da COVID-19 & 97,2 & $1,4 \%$ \\
\hline Total & 607,2 & $8,6 \%$ \\
\hline
\end{tabular}

Somando-se às transferências e subsídios da Tabela 2 outras reduções indiretas de impostos e outros ajustes, chega-se a um aumento nominal de 10,5\% do PIB na renda disponível do setor privado e a uma queda equivalente na renda disponível do setor público (vide metodologia no Anexo 1). Os impactos deste aumento de renda disponível do setor privado sobre os fluxos macroeconômicos não são triviais, dadas as características das transferências e as restrições ao consumo dos produtos do setor circo impostas pela pandemia.

Um primeiro efeito tem a ver com o público-alvo. Como mostra a Tabela 2 acima, um componente importante das transferências foi dirigido à população mais vulnerável, através, principalmente, do auxílio emergencial, da ampliação do Bolsa família e das complementações de renda por jornada reduzida ou suspensão do contrato de trabalho. Como os receptores destas transferências tendem a ter uma elevada propensão a consumir, somos levados a supor que haveria um aumento da participação do consumo na renda.

Alguns trabalhos empíricos recentes reforçam a hipótese acima. Estudo do IPEA (Carvalho 2020) mostrou que, até o mês de setembro, somente o auxílio emergencial superava em $54 \%$ a redução da massa salarial dos que permaneciam ocupados. Por outro lado, estudo de Neri (2020) mostrou que houve uma redução de 13,4 milhões do número de pobres como consequência do auxílio emergencial, ao mesmo tempo em que ocorreu uma redução de 5,6 milhões de pessoas nos estratos com renda superior a 2 salários mínimos, como consequência da pandemia, 
ambos os fenômenos concorrendo para um achatamento da distribuição de renda. Em suma, todos esses movimentos na distribuição de renda contribuem para um aumento da propensão a consumir na sociedade.

Por outro lado, as camadas de renda média e alta da população, cuja participação dos serviços na pauta de consumo é muito elevada, foram forçados a poupar, o que aumenta a taxa de poupança e diminui a participação do consumo na renda.

$\mathrm{Na}$ verdade, ambos os fenômenos ocorreram (aumento do consumo e da poupança). Isto parece a princípio contraditório, mas não é. A rigor, como mostraremos na segunda seção a seguir, a poupança privada cresce em detrimento da poupança pública e não em detrimento do consumo.

Ainda que tenha suas especificidades, as consequências da COVID-19 e das políticas para enfrentá-las estão longe de serem diferentes no Brasil do que ocorreu em muitos outros países. Na seção a seguir, que discutirá as mudanças nos fluxos macroeconômicos, faremos uma breve referência a dados internacionais que mostram fenômenos muito semelhantes aos verificados no Brasil.

\section{O FINANCIAMENTO DO DÉFICIT}

Vimos anteriormente que o déficit nominal do governo geral deve quase triplicar em relação ao valor observado em 2019, alcançando um valor inédito (em \% do PIB) desde o Plano Real. Parece haver um consenso entre economistas, tanto no Brasil quanto no exterior, a respeito do fato de que, em frente ao desafio colocado pela COVID-19, era necessário fazer tudo o que fosse necessário - inclusive incorrer em déficits fiscais sem precedentes - para enfrentar as consequências econômicas e sociais da pandemia.

Ainda assim, há um desafio a ser enfrentado: como financiar esse déficit tão elevado? O problema do financiamento do déficit público pode ser tratado através de duas óticas: a dos instrumentos de financiamento e a dos fluxos macroeconômicos.

Pela ótica dos instrumentos utilizados, o déficit pode ser financiado através da colocação de títulos da dívida pública, pela emissão de moeda ou pela liquidação de ativos (no caso brasileiro atual, principalmente reservas internacionais). Enquanto alguns, como Bresser-Pereira (2020) e Resende (2020), defendem o uso massivo do financiamento monetário, outros, como Garcia e Mendes (2020), (Pessoa 2020) e Rajan (2020), apontam a limitação deste instrumento no contexto do sistema de metas inflacionárias. Trata-se aqui de uma discussão sobre as possibilidades e limites da política monetária no atual contexto de pandemia, que foge ao escopo do presente texto.

Nosso foco é o financiamento do ponto de vista macroeconômico, independentemente dos instrumentos utilizados. Assumiremos então, como um dado, o tipo de financiamento que vem sendo realizado no Brasil, que combina os três instrumentos mencionados, porém com a predominância da colocação de títulos da dívida pública. De fato, desde março, quando começou a epidemia no Brasil, até setembro último, tivemos a seguinte participação dos principais instrumentos: a dívida mobiliária em poder do público (incluindo operações compromissadas) teve 
uma expansão de R 798 bilhões (+15\%), a base monetária cresceu R 106 bilhões $(+35 \%)$ e a venda de reservas internacionais somou R\$ 112 bilhões $^{3}$.

Contudo, independentemente do instrumento utilizado, o setor privado ou o resto do mundo deverão financiar o déficit pela absorção de títulos públicos, moeda nacional ou moeda estrangeira em seus ativos. Em outras palavras, há uma questão de financiamento macroeconômico, e a esta questão nos dirigiremos.

A questão que trataremos a seguir pode ser assim enunciada: se o déficit público sobe de $6 \%$ do PIB para 17,4\% do PIB, como este "elefante vai ser acomodado na sala"? Ou seja, como os demais agregados macroeconômicos se reacomodarão (como \% do PIB)?

Para tratar desta questão, lembremos que uma parcela expressiva do aumento do déficit deveu-se não a aumento de gastos de consumo do governo e sim ao aumento de transferências de renda ao setor privado, implicando uma mudança importante da composição da renda disponível dos chamados setores institucionais da economia.

Comecemos, pois, pela desagregação da renda nacional disponível bruta (RDB) por setores institucionais.

$$
\mathrm{RDB}=\mathrm{RDG}+\mathrm{RDSPRIV}
$$

Onde:

RDG é a renda disponível do governo, igual à receita do governo geral com impostos (diretos e indiretos) mais taxas e contribuições, menos juros da dívida pública, subsídios e transferências (T-Jg-S-Tr).

A RDSPRIV é a soma da renda disponível das famílias (salários, aluguéis, dividendos, etc., mais transferências recebidas do governo, menos impostos sobre a renda e o patrimônio) com a renda disponível das empresas (lucros retidos menos impostos sobre os lucros) e das instituições sem fins de lucro.

Dividindo ambos os lados da equação (1) pelo PIB, temos:

$\mathrm{rdb}=\mathrm{rdg}+$ rdspriv

Pela ótica dos gastos, podemos escrever:

$r d b=c+g+i+t c$ (todas as variáveis medidas em \% do PIB)

E, substituindo (2) em (3):

$\mathrm{rdg}+\mathrm{rdspriv}=c+g+i+t c$

Para colocar a equação de uma forma a explicitar as transferências de renda entre setores institucionais e suas consequências, vamos prosseguir modificando (4) para que expresse a decomposição da renda disponível do setor privado:

$$
\text { rdspriv }=c+(g-r d g)+i+t c
$$

\footnotetext{
${ }^{3}$ Cálculo aproximado, a partir dos dados de intervenção no "pronto", multiplicados pela taxa de câmbio média de cada mês.
} 
Como a poupança do governo é sua renda disponível menos seus gastos de consumo (rdg -g), temos que:

$$
g-\mathrm{rdg}=-\mathrm{sg}
$$

E substituindo (6) em (5):

$$
\text { rdspriv }=c-s g+i+t c
$$

Rearranjando:

$$
r d s p r i v-c=i-s_{g}+t c
$$

Subtraindo-se o consumo das famílias da renda disponível do setor privado, tem-se, no lado direito da equação, a poupança do setor privado, como proporção do PIB ( $\left.\mathrm{s}_{\text {priv }}\right)$

$$
s_{\text {priv }}=i-s_{g}+t c
$$

Desagregando o investimento total em investimento privado $\left(i_{\text {priv }}\right)$ e investimento do governo $\left(i_{\mathrm{g}}\right)$, temos:

$$
s_{\text {priv }}=i_{\text {priv }}+\left(i_{g}-s_{g}\right)+t c
$$

Onde:

$$
i_{g}-s_{g}=n f g g
$$

(necessidade de financiamento do governo geral, como proporção do PIB).

Podemos escrever então:

$$
n f g g=s_{\text {priv }}-i_{\text {priv }}+d t c
$$

onde dtc $=-$ tc $=$ déficit em transações correntes.

A equação (12) pode ser lida como indicando que a as necessidades de financiamento do governo geral vão ser supridas pelo excesso da poupança privada sobre o investimento privado e pela poupança externa (o déficit em conta-corrente do balanço de pagamentos).

Podemos agora calcular os valores das variáveis da equação (12) para identificar como o forte aumento do déficit público foi financiado. Os métodos para estimar os valores para o ano de 2020 completo, a partir dos dados disponíveis até o momento, estão descritos no Anexo 1.

A Tabela 3 a seguir traz resultados surpreendentes. Para que se possa apreciar a grandeza das mudanças nos fluxos macroeconômicos com a pandemia, as duas primeiras linhas trazem os valores das variáveis da equação (12) para o período 2000-2019 (média histórica) e 2019 (pré-pandemia), respectivamente. Como se pode ver, as necessidades de financiamento do governo geral tiveram um extraordinário aumento: 12,5 pontos percentuais do PIB em relação à média histórica e $11,3 \%$ em relação ao ano anterior à pandemia (a diferença de $0,1 \%$ se deve à segunda casa decimal).

Uma possibilidade teórica (e comum no passado) de financiamento deste aumento de $11,3 \%$ do PIB nas $n f g g$ seria através do recurso à poupança externa. Este, en- 
tretanto não é o caminho que vem sendo trilhado. Ao contrário, desde o início da pandemia, por razões que não cabe aqui discutir, as transações correntes se tornaram superavitárias. E, a julgar pelos dados mais recentes do balanço de pagamentos, mesmo a queda do déficit de 1,9\% do PIB, que consta da tabela, talvez esteja subestimada. Enfim, sobra para o setor privado, através de um aumento na sua capacidade de financiamento $\left(\mathrm{s}_{\text {priv }}-\mathrm{i}_{\text {priv }}\right)$, financiar não apenas o aumento das $n f g g$, mas também um pequeno aumento no saldo em transações correntes (ou diminuição do déficit).

A tarefa é hercúlea. Mas com os dados já disponíveis é possível afirmar que nada muito diferente dos números abaixo tende a ocorrer. Ou seja, o excesso da poupança privada sobre o investimento privado terá que ser da ordem de $16 \%$ do PIB ou cerca de $13 \%$ do PIB acima do nível pré-pandemia. Isto poderia ocorrer através de um colapso do investimento privado. Mas os dados disponíveis até o mês de agosto sugerem que este não é o caso. O investimento privado deve cair um pouco mais do que o PIB, mas não o suficiente para fazer uma diferença maior do que poucas casas decimais em percentagem do PIB.

Em suma, as estimativas da Tabela 3 a seguir nos levam a concluir que a poupança privada deverá se elevar de cerca de $16,8 \%$ do PIB em 2019 para 30\% em 2020. Mas como isso poderá ocorrer?

Tabela 3: O financiamento das nfgg na pandemia

\begin{tabular}{|c|c|c|c|c|c|}
\hline Ano & nfgg & $S_{\text {priv }}{ }^{(1)}$ & $\mathrm{i}_{\text {priv }}$ & $\begin{array}{l}\text { Capacidade de } \\
\text { financiamento } \\
\text { do Setor Privado } \\
\text { (Spriv- i loriv) }\end{array}$ & $\mathrm{tc}^{(2)}$ \\
\hline $\begin{array}{l}\text { Média histórica } \\
\text { (2000-2019) }\end{array}$ & $4,9 \%$ & $18,7 \%$ & $15,6 \%$ & $3,1 \%$ & $-2,3 \%$ \\
\hline $\begin{array}{l}\text { Pré-pandemia } \\
\text { (2019) }\end{array}$ & $6,2 \%$ & $16,8 \%$ & $13,6 \%$ & $3,2 \%$ & $-2,9 \%$ \\
\hline 2020 & $17,4 \%$ & $30,0 \%$ & $13,5 \%$ & $16,4 \%$ & $-1,0 \%$ \\
\hline D (2020 - 2019) & $11,3 \%$ & $13,1 \%$ & $0,0 \%$ & $13,2 \%$ & $1,9 \%$ \\
\hline
\end{tabular}

Fontes: Banco Central do Brasil, Séries Temporais e Relatório de Inflação; IBGE, Contas Nacionais Trimestrais e Contas Anuais; Ministério da Economia, Análise do Impacto Fiscal das Medidas de Enfrentamento à Covid-19 (28/10/2020).

Elaboração do autor.

(1) inclui toda a variação de estoques.

(2) paro o período 2000-2019, pelo critério das contas nacionais.

Antes de tentar explicar como está sendo possível esse extraordinário salto no nível da poupança doméstica no Brasil, é interessante observar que não se trata, em absoluto, de um fenômeno local. Pelo contrário, podemos considerar como uma das regularidades nesta pandemia, que ao aumento das transferências dos governos para os setores privados corresponde também um aumento substancial da poupança do setor privado. A Tabela 4 a seguir mostra, para economias avançadas, dados até o segundo trimestre de 2020 que registram tais movimentos. No caso extremo dos EUA, a renda pessoal disponível sobe 18 pontos percentuais do PIB entre o $2^{\circ}$ trimestre de 2019 e o $2^{\circ}$ trimestre de 2020 , enquanto a poupança privada sobe 19 pontos percentuais (de $7 \%$ da renda pessoal disponível para $26 \%$ ). 
Tabela 4: Renda Pessoal Disponível/PIB e taxa de

poupança privada em Economias Avançadas

\begin{tabular}{l|ccc|ccc} 
& \multicolumn{3}{|c|}{ Renda Pessoal Disponível/PIB } & \multicolumn{3}{c}{ Poupança/Renda Pessoal Disponível } \\
\cline { 2 - 7 } País/Região & 2 T 2019 & 1 T 2020 & 2 T 2020 & 2 T 2019 & 1 T 2020 & 2 T 2020 \\
União Europeia & $62 \%$ & $61 \%$ & $68 \%$ & $12 \%$ & $16 \%$ & $24 \%$ \\
Área Euro & $64 \%$ & $62 \%$ & $71 \%$ & $13 \%$ & $17 \%$ & $25 \%$ \\
Reino Unido & $61 \%$ & $55 \%$ & $71 \%$ & $7 \%$ & $10 \%$ & $30 \%$ \\
Estados Unidos & $76 \%$ & $77 \%$ & $94 \%$ & $7 \%$ & $10 \%$ & $26 \%$ \\
\hline
\end{tabular}

Fontes: Eurostat, USDOC/BEA e UK Office of National Statistics.

Muito ainda terá que ser investigado empiricamente para chegar-se a um diagnóstico acurado do fenômeno acima. Porém, e agora voltando especificamente ao caso brasileiro, algumas pistas já podem ser exploradas, que nos dão indicações do que vem ocorrendo.

Sabemos que uma parte preponderante das transferências do governo foram para as populações de renda mais baixa, que tem maior propensão a consumir, o que levaria a um resultado oposto ao mostrado na Tabela 3.

Estudo do Banco Central publicado no Relatório de Inflação de setembro (Banco Central 2020, 31) sugere que a propensão marginal a poupar a partir do auxílio emergencial foi baixa, mas não tanto $(0,17 \%$ em média). Mas a renda da população mais pobre subiu muito, e outro estudo publicado no mesmo relatório (Banco Central 2020,37) mostra que os gastos de consumo (com cartão de crédito e pagamento de boletos), no quartil inferior da renda, baixou pouco no início da pandemia e logo se recuperou, superando bastante os níveis pré-pandemia a partir de junho, o que sugere que o destino do auxílio emergencial foi principalmente o consumo e não a poupança. Já no quartil superior, o consumo caiu mais e se mantinha, até junho, bem abaixo dos níveis pré pandemia.

As evidências acima são compatíveis com as hipóteses anteriormente levantadas: o auxílio emergencial e as demais transferências do governo aumentaram o déficit público. Porém, tais transferências governamentais aumentaram a renda disponível do setor privado - uma parte deste aumento sendo alocada para mais consumo e outra parte a mais poupança privada. Por outro lado, a restrição às atividades - e, portanto, - ao consumo de bens e serviços intensivos em contato, típicos da cesta de consumo das camadas da população de alta renda, elevaram sua propensão a poupar.

Em suma, a renda do setor privado subiu (muitíssimo como proporção do PIB) por causa das transferências recebidas do governo, enquanto o consumo baixou, por causa das restrições associadas à pandemia.

Se é assim a pandemia criou, ao mesmo tempo um grande problema fiscal e a sua solução. A "poupança forçada" das camadas da população de renda mais alta, que resultou da pandemia e de seu enfrentamento, foi canalizada para os instrumentos financeiros postos à disposição pelo setor público: moeda, dívida pública e reservas internacionais. Os números das Tabelas 3 e 4 são, pelo menos, consistentes com esta explicação. 


\section{FLUXOS E ESTOQUES: CONSEQUÊNCIAS DA PANDEMIA PARA A DISTRIBUIÇÃO DE RIQUEZA}

As mudanças nos fluxos macroeconômicos resultantes da pandemia resultaram em grandes transferências de renda e mudanças nas participações do consumo e da poupança na renda dos diferentes setores institucionais da economia. A despoupança do setor público e a poupança do setor privado tiveram variações sem precedentes num curto período de tempo. Mas fluxos de poupança e despoupança afetam os estoques de riqueza na sociedade. Uma maneira de medir isso é através da construção de matrizes de ativos e passivos por setores institucionais.

$\mathrm{Na}$ Tabela 5 abaixo construímos uma matriz de ativos e passivos financeiros (estão excluídos os ativos reais) de 3 macrossetores institucionais no mês imediatamente anterior à pandemia: o setor privado (famílias, empresas financeiras e não financeiras e entidades sem fins lucrativos), o governo geral e o Banco Central, e, por fim, o setor externo ou resto do mundo.

\section{Tabela 5: Matriz de Estoques: Ativos e Passivos Financeiros por Setor Institucional, em fev/2020 (\% PIB)}

\begin{tabular}{cccccc} 
Setores & $\begin{array}{c}\text { Setor Privado } \\
\text { (FIN + NF) }\end{array}$ & $\begin{array}{c}\text { Setor Público (1) } \\
\text { (gov+BC) }\end{array}$ & $\begin{array}{c}\text { Setor } \\
\text { Externo }\end{array}$ & $\begin{array}{c}\text { Total } \\
\text { de Ativos }\end{array}$ & $\begin{array}{c}\text { Riqueza } \\
\text { Financeira Líquida } \\
\text { (Ativos - Passivos) }\end{array}$ \\
Setor Privado (F + NF) & - & 81,4 & 32,9 & 114,3 & 23,2 \\
Setor Público (gov+BC) & 11,8 & - & 22,3 & 34,2 & $-58,1$ \\
Setor Externo & 79,3 & 10,9 & - & 90,1 & 34,9 \\
Total de Passivos & 91,1 & 52,3 & 55,2 & 238,6 & 0,0 \\
\hline
\end{tabular}

Fontes: Banco Central do Brasil, Posição do Investimento Internacional, Panorama do Banco Central, Notas para a Imprensa, Fiscal e Setor Externo. Elaboração do autor.

(1) A base monetária foi incluída nos passivos do governo geral + Banco Central.

Nas colunas estão computados os passivos de cada setor institucional. Assim, os passivos do setor público (dívida interna, externa e base monetária) correspondiam, no mês de fevereiro, a 92,3\% do PIB, estando $81,4 \%$ em mãos do setor privado doméstico e 10,9\% em mãos de não residentes. Nas linhas estão representados os ativos. No caso do setor público eles correspondiam a $34,2 \%$ do PIB, sendo $11,8 \%$ ativos domésticos emitidos pelo setor privado e $34,2 \%$ ativos externos (a quase totalidade constituída por reservas internacionais). Por fim, na última coluna está computada a riqueza líquida ou patrimônio líquido (total dos ativos financeiros menos passivos financeiros) de cada setor institucional.

A fim de poupar o leitor, omitimos aqui a matriz pós-pandemia, que pudemos construir, com os dados disponíveis, para o mês de agosto de 2020. Em vez disso, construímos uma tabela (6), contendo apenas a riqueza financeira líquida dos 3 setores institucionais para os meses de fevereiro (pré-pandemia) e agosto (pandemia) de 2020. Note-se que neste último mês uma parcela importante das mudanças nos fluxos macroeconômicos já havia ocorrido.

Os resultados são impactantes. Em poucos meses ocorreu uma drástica mu- 
dança nas posições da riqueza financeira líquida dos setores. O passivo líquido do setor público aumentou quase 12 pontos percentuais do PIB. E a riqueza privada líquida aumentou praticamente pelo mesmo valor.

A riqueza líquida do resto do mundo em relação ao país diminuiu por um valor muito pequeno, correspondente aos superávits acumulados em conta-corrente, no período março-agosto de 2020. A propósito, cabe notar que as mudanças nas posições das riquezas financeiras líquidas dos setores institucionais decorrem principalmente dos fluxos macroeconômicos, mas também de mudanças de preços de ativos e passivos, incluindo a taxa de câmbio. Como a forte desvalorização do real no período teve um impacto não desprezível nestas medidas (e, se revertida, terá um efeito contrário), resolvemos, na Tabela 6, fazer um ajuste para descontar tais variações. Assim, no caso do setor externo, calculamos as variações apenas pelos fluxos, sem considerar variações de preços, inclusive câmbio.

Tabela 6: Riqueza Financeira Líquida por Setor Institucional (\% PIB) (1)

\begin{tabular}{|c|c|c|c|}
\hline Setores & Pré-Pandemia (fev/2020) & Pandemia (ago/2020) & Variação ago/20 - fev/20 \\
\hline Setor Privado $(F+N F)$ & 23,2 & 35,1 & 11,9 \\
\hline Setor Público $(\text { gov+BC) })^{(2)}$ & $-58,1$ & $-69,9$ & $-11,8$ \\
\hline Setor Externo & 34,9 & 34,8 & $-0,1$ \\
\hline \multicolumn{4}{|c|}{$\begin{array}{l}\text { (1) Valores de agosto de } 2020 \text { para o setor externo calculados pelos efeitos dos fluxos do balanço de pagamentos sobre os estoques de } \\
\text { fevereiro/ } 2020 \text {. } \\
\text { (2) A base monetária foi incluída nos passivos do governo geral + Banco Central. } \\
\text { Fontes: Banco Central do Brasil, Posição do Investimento Internacional, Panorama do Banco Central, Nota para a Imprensa: Estatísticas } \\
\text { Fiscais e do Setor Externo. }\end{array}$} \\
\hline
\end{tabular}

\section{IMPLICAÇÕES SUGERIDAS PELA ANÁLISE ANTERIOR}

No presente texto analisamos algumas características centrais de uma macroeconomia da pandemia, que estão presentes em inúmeros países assolados pela COVID-19, entre eles o Brasil. Já passados 7 meses da pandemia no Brasil, pudemos lançar mão de informações estatísticas que permitem dar uma dimensão numérica às variáveis macroeconômicas afetadas pela pandemia e pelas respostas da política econômica a elas.

Identificamos, primeiramente, uma dualidade na economia, com a existência de um setor interditado (ou semi-interditado), que denominamos de setor circo, por implicar aglomerações. Este setor opera com demanda e oferta muito abaixo do potencial. Mas a economia abriga um outro setor que não apenas está destravado, mas cuja demanda é sobreaquecida pelas políticas de transferência de renda, e que denominamos de setor pão.

O outro traço marcante da macroeconomia da pandemia é a forte distribuição de renda (setorial, regional e pessoal), concentrada num curto período de tempo, que resulta das medidas de enfrentamento da pandemia. Neste trabalho nos concentramos nos efeitos da distribuição de renda entre setores institucionais. Mostra- 
mos que no centro desse processo redistributivo está a elevação do déficit público em cerca de $11 \%$ do PIB, uma boa parte deste aumento sendo resultante do aumento de transferências, que resultaram em forte queda da renda disponível do setor público, lado a lado com grande aumento da renda disponível do setor privado (como proporção do PIB).

Vimos que, se o setor público aumentou muito sua dívida pública por causa do déficit causado pelas medidas de enfrentamento da pandemia, por outro lado a poupança privada aumentou num montante equivalente, tornando mais fácil a absorção desta dívida ampliada. Além disso, foi um aumento de dívida de residentes (o governo geral brasileiro) com residentes (o setor privado doméstico), o que torna também mais manejável (embora não isenta de problemas) a dívida ampliada.

Neste sentido, não me parece apropriada a noção de que a geração presente deixou uma dívida para a geração futura. Como a dívida adicional é toda interna, deixou-se uma dívida, mas também uma riqueza financeira da mesma magnitude da dívida para as gerações futuras. Se fosse possível taxar a riqueza financeira adicional para liquidar a dívida adicional, o problema estaria resolvido. Como isso dificilmente seria viável, o problema que fica é que uma dívida maior sempre traz maior instabilidade futura, sempre que houver aumento da incerteza e da aversão ao risco na economia.

Além disto, a distribuição de renda, que beneficiou os mais pobres durante a pandemia, cessa com o fim do auxílio emergencial. Mas a riqueza financeira líquida ampliada do setor privado, concentrada em mãos das parcelas mais ricas da sociedade, tenderá a pesar negativamente sobre a distribuição de renda futura (pelo recebimento de juros). Temos então um agravamento do problema distributivo pela frente.

No que se refere à questão mais conjuntural ou cíclica de recuperação em relação à pandemia, note-se que a dualidade da economia impõe um limite ao retorno da produção aos níveis anteriores. A solução, neste caso, não está na política macroeconômica e sim na vacina. Só com o fim do risco associado aos contatos e aglomerações será possível restabelecer plenamente a produção no setor circo, que compõe uma parte importante da produção e do emprego agregados.

Por fim, a esperança frequentemente aventada de que a expansão dos gastos de consumo da classe média e das classes de renda mais alta, através do uso da poupança acumulada no período mais agudo da pandemia, poderá compensar a queda do consumo derivada do fim do auxílio emergencial é vã. E não apenas pela interdição parcial da economia referida no parágrafo anterior. Também por uma razão financeira: quem comprará os títulos da dívida pública a serem liquidados por estes poupadores? Se por novos poupadores, o efeito líquido é nulo. Se pelo governo, teria que haver um mega-ajuste fiscal que compensaria o maior gasto dos novos consumidores. 


\section{REFERÊNCIAS BIBLIOGRÁFICAS}

Aronson, Jeffrey K, Jon Brassey, e Kamal R Mahtani.(2020) “'When will it be over?”: An introduction to viral reproduction numbers, R0 and Re.” CEBM Research, 2020

Baldwin, Richard, e Beatrice Weder di Mauro. (2020) "Introduction." In Richard Baldwin e Beatrice Weder di Mauro (eds) Mitigating the COVID Economic Crisis: Act Fast and Do Whatever It Takes: 1-24. Londres: CEPR Press.

Banco Central. (2020) “Auxílio emergencial e compras com cartão de débito.” Relatório de Inflação. Setembro: 31-33.

Banco Central.(2020) “Consumo por quartil de renda durante a pandemia.” Relatório de Inflação. Setembro: $37-39$.

Bresser-Pereira, Luiz Carlos. (2020) "Financiamento da Covid-19, inflação e restrição fiscal.” Brazilian Journal of Political Econ omy, Out-dez: 604-621.

Carvalho, Sandra Sacchet. (2020) "Os efeitos da pandemia sobre os r'endimentos do trabalho e o impacto do auxílio emergencial: os resultados dos microdados da PNAD Covid-19 de setembro." Carta de Conjuntura IPEA, ${ }^{\circ} 49$ (outubro): 1-17.

Confederação Nacional da Indústria. (2020) “Sondagem Especial.” Vol. 20. Brasília: CNI, outubro.

Correia, Sergio, Stephan Luck, e Emil Verner. (2020) "Pandemics Depress the Economy, Public Health Interventions Do Not: Evidence from the 1918 Flu.” Texto ainda não publicado, disponível em https://ssrn.com/abstract=3561560, 2020.

Garcia, Márcio, e Marcos Mendes. (2020) "Não há Mágica.” Folha Online. 06 de Março de 2020. www.econ.puc-rio.br/uploads/adm/trabalhos/files/200406_Monetizacao_v04.pdf.

Gourinchas, Pierre-Olivier. (2020) "Flatenning the pandemic and recession curves." In Richard Baldwin e Beatrice Weder di Mauro (eds) Mitigating the COVID Economic Crisis: Act Fast and Do Whatever It Takes: 1-24. Londres: CEPR Press: 31-39.

International Monetary Fund. (2020) “Fiscal Monitor.” Washington, DC: International Monetary Fund, Publication Services, October.

Keynes, John Maynard (1940) How to pay for the war: a radical plan for the Chancellor of the Exchequer. London: MacMillan and Co.

Neri, Marcelo. (2020) "Qual foi o impacto imediato da pandemia do Covid sobre as classes econômicas brasileiras?” FGV Social.

Pessoa, Samuel. (2020) “Imprimir dinheiro contra a crise?” Folha de São Paulo. 03 de maio de 2020.

Rajan, Raghuram G. (2020) "Monetization: Neither Game Changer nor Catastrophe in Abnormal Times.” https://faculty.chicagobooth.edu/-/media/faculty/raghuram-rajan/articles/monetization---neither-game-changer-nor-catastrophe.pdf. Maio de 2020.

Resende, André Lara. (2020) “Crise exige superar equívocos sobre emissão de moeda e dívida pública." Folha de São Paulo. 17 de maio de 2020.

\section{ANEXO 1}

\section{Método utilizado para projetar, para o ano de 2020, os valores de agregados macroeconômicos empregados neste trabalho}

As informações do IBGE sobre a renda disponível dos setores público e privado, e suas decomposições entre poupança e consumo, para 2020, são essenciais para a análise realizada neste texto, mas só deverão estar disponíveis dentro de 2 anos, quando forem divulgadas as contas nacionais anuais para 2020. Contudo, usando-se os dados das contas nacionais trimestrais e as estatísticas do Banco Central, bem como as estimativas do Ministério da Economia para as contas do governo central, é possível fazer uma estimativa daquelas variáveis. Apresenta-se a seguir o método utilizado para construir esta estimativa.

Neste trabalho focamos nossa análise nas contas do governo geral mais Banco Central. 
Ou seja, o conceito de governo que estamos utilizando difere do conceito de setor público consolidado pela exclusão das empresas estatais federais, estaduais e municipais, que estão incluídas neste último.

Nosso ponto de partida é a identidade:

$\mathrm{NFGG}=\mathrm{Ig}-\mathrm{Sg}$

Onde:

NFGG = necessidades de financiamento do governo geral, que podem ser estimadas a partir das estatísticas “abaixo da linha”, divulgadas pelo Banco Central.

Ig e Sg são, respectivamente, o investimento e a poupança do governo.

Os valores do investimento público estão disponíveis até 2019 e seus valores para 2020 são estimados pelo Ministério da Economia. Podemos então calcular o valor da poupança do governo geral:

$$
\mathrm{Sg}=\mathrm{NFGG}-\mathrm{Ig}
$$

Os gastos de consumo do governo $(\mathrm{G})$ estão disponíveis nas contas nacionais trimestrais (neste momento até o $2^{\circ}$ trimestre de 2020) e podem ser projetados para o final de 2020 a partir de informações do Ministério da Economia. Com isso pode-se estimar a renda disponível do governo (RDG):

$$
\mathrm{RDG}=\mathrm{G}+\mathrm{Sg}
$$

E substituindo (2) em (3):

$$
\mathrm{RDG}=\mathrm{G}+\mathrm{NFGG}-\mathrm{Ig}
$$

A renda nacional disponível bruta (RDB) foi projetada a partir da nossa projeção do PIB (4,9\% abaixo do PIB de 2019), somada aos valores projetados para as rendas primárias e secundárias, cujos valores já estão disponíveis, nas estatísticas do balanço de pagamentos, até o mês de setembro de 2020. A partir da RDB pode-se então chegar à renda disponível do setor privado (RDSP):

$$
\mathrm{RDSP}=\mathrm{RDB}-\mathrm{RDG}
$$

$\mathrm{E}$, sendo "C" o consumo das famílias, a poupança do setor privado (Sp) fica sendo:

$$
\mathrm{Sp}=\mathrm{RDSP}-\mathrm{C}
$$

Ou ainda, usando a identidade das contas nacionais entre as somas das poupanças privada, governamental e externa e o investimento:

$$
\begin{aligned}
& S p+S g-T C=I \\
& S p=I-S g+T C
\end{aligned}
$$

Pode-se então projetar a poupança do setor privado para 2020 de duas maneiras: ou usando (6), pela projeção para o consumo das famílias (C), cujos dados já se encontram disponíveis até o $2^{\circ}$ trimestre de 2020; ou usando-se (8), cujos dados para investimento e transações correntes, além de estarem disponíveis nas contas nacionais trimestrais, podem ser estimados para meses posteriores ao $2^{\circ}$ trimestre, a partir das informações sobre consumo aparente de bens de capital e construção civil, de um lado, e dos dados do balanço de pagamentos, de outro. Por contar com estas informações mais completas, preferimos, neste trabalho, usar a equação (8) para estimar a poupança do setor privado. 